\title{
Patient flow in the Post
}

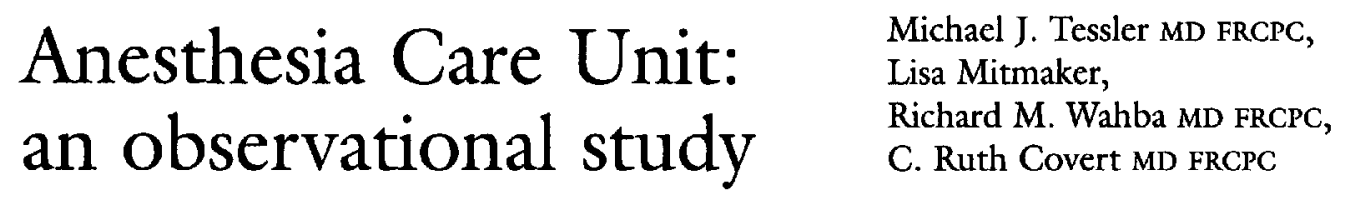

Purpose: Anesthesiologists are constantly striving for improvement in health care delivery. We assessed the patient flow in the Post Anesthesia Care Unit (PACU) to determine if patients are being transported out of the PACU when ready.

Methods: A University student recorded the flow of 336 patients who recovered in our Post Anesthesia Care Unit. The corresponding nursing and orderly complements were recorded. If a delay arose between the time the patient was deemed fit for discharge by the PACU nurse and the time the patient was transported from the PACU, the student determined the duration and cause(s) of the delay.

Results: The number of patients, nurses, and orderlies increased from three to twelve, three to seven, and one to two respectively throughout the elective working day. Seventy-six per cent of patients studied were delayed in transport from the PACU, with $26 \%$ of patients waiting 30 min. The average delay in discharge for patients increased during the day from 0 to $65 \pm 54 \mathrm{~min}$ from the time of fit for discharge, as determined by the PACU nurse, until transport. Five causes were identified as contributing to the delay: orderly too busy (41\%), awaiting Anesthesia assessment (36\%), Post Anesthesia Care Unit nurse too busy (15\%), receiving floor not ready (6\%), and patient awaiting radiographic interpretation (2\%).

Conclusion: Our study has shown that system errors unnecessarily prolongs the stay of patients in the PACU.

Objectif : Les anesthésiologistes s'efforcent constamment d'améliorer les soins de santé. Nous avons évalué le débit de patients à la salle de réveil afin de déterminer s'ils sont transportés à l'extérieur de la salle dès qu'ils sont prêts.

Méthode : Un étudiant d'université a enregistré les déplacements de 336 patients en récupération dans notre salle de réveil. II a noté les effectifs infirmier et aide-infirmier correspondant. Si un délai survenait entre le moment où l'infirmière jugeait que le patient était prêt à quitter la salle et le moment où il était transporté, l'étudiant déterminait la durée et la ou les cause(s) de ce délai.

Résultats : Le nombre de patients, d'infirmières et d'aides a augmenté de trois à douze, de trois à sept et de un à deux respectivement au long de cette journée de travail. Soixante-seize pour cent des patients étudiés ont connu un délai de transport, dont $26 \%$ ont dû attendre $30 \mathrm{~min}$. Le délai moyen d'attente pour les patients s'est accru pendant la journée, passant de 0 à $65 \pm 54 \mathrm{~min}$. Cinq causes ont été identifiées comme ayant contribué au délai : les aides-infirmiers sont trop occupés ( $41 \%$ ), on attend l'évaluation anesthésique (36\%), l'infirmière de la salle de réveil est trop occupée (15\%), la chambre du malade n'est pas prête $(6 \%)$ et le patient attend l'interprétation radiographique (2\%).

Conclusion : Notre étude a montré que des erreurs d'organisation prolongent inutilement le séjour des patients en salle de réveil.

From the Department of Anesthesia SMBD-Jewish General Hospital and McGill University, 3755 Cote Ste. Catherine Road, Montreal, Quebec, Canada H3T 1E2.

Address correspondence to: Michael J. Tessler MD. Phone: 514-340-8222, ext. 5701; Fax: 514-340-7510; E-mail: mtessler@ana.jgh.mcgill.ca

Ms. Mitmaker was funded by the SMBD-Jewish General Hospital Department of Anesthesia Fund.

Accepted for Publication February 3, 1999 
$\mathrm{T}$ HE Post Anesthesia Care Unit (PACU) is an area where patients of varying severity of illness recover following invasive procedures. It is also an area with a high staff-topatient ratio. The annual budget for the PACU at our institution is $\$ 920,000$ of which $\$ \mathbf{8 8 5 , 0 0 0}$ is for salaries. The PACU is, therefore, an area where patients should not linger unnecessarily because of the potential effect on the cost of health care delivery.

We have had and continue to have considerable budgetary constraints at the SMBD-Jewish General Hospital. We have previously examined the impact of education on improving Operating Room (OR) start times, ${ }^{1}$ of individual anesthesiologists on room turnover ${ }^{2}$ and the time difference between spinal and general anesthesia for vaginal hysterectomy. ${ }^{3}$ We undertook the present study to examine the flow of patients through our PACU. We thought that, by first examining the patient flow, we might find ways of improving patient care without increasing the PACU costs.

\section{Methods}

The SMBD-Jewish General Hospital is a tertiary care university-affiliated hospital. All major surgical subspecialties except pediatrics and organ transplantation are represented in the 11 room operating suite. Our elective surgical schedule from Monday to Friday is eight anesthesia and one monitored anesthesia care (MAC) rooms from 0745 until 1530 . After 1530 we reduce to five rooms, including emergency procedures. Approximately 8,500 patients, including emergencies, recover in our 19 bed PACU following a surgical intervention.

The observations in patient flow were made by (LM), a university student, studying business administration. The student was present from 07:30 until 16:00 Monday to Friday inclusive over a six week period from May 5th until June 12th, 1998. This period is representative of our PACU function because there are no national anesthesia conferences or holiday breaks. The student recorded the following: type of anesthetic, the time the patient entered the PACU, the time the patient was deemed fit for discharge from the PACU as determined by the PACU nurse, and the time the patient actually left the PACU. If a patient was ready to leave but was delayed, the time delay caused by one of the following causes was evaluated by LM and recorded: the PACU orderlies were busy, the patient had yet to be assessed by an anesthesiologist, the receiving ward nurses were not ready to accept a new patient, the PACU nurse was too busy to transfer, or the patient was awaiting the interpretation of an Xray or other test. Each patient was counted once. If a patient was delayed because of more than one cause, each cause was ascribed as contributing.

A modified Aldrete score, which gives an optimal score of 2 for each of patient mobility, respiration, circulation, level of consciousness, and colour, and is performed by the PACU nurse, and was used to assess patient fitness for discharge. ${ }^{4} \mathrm{~A}$ score of 10 is required in our institution for a patient to be discharge ready. There is no minimum length of stay for any patient in our PACU, other than those specified upon admission.

The PACU has five eight hour nursing shifts over $24 \mathrm{hr}$. The usual PACU week day schedule will have three nurses from 07:30 to 15:30, three nurses from 10:00 to 18:00, one nurse from 12:00 to 20:00, three nurses from 15:30 to $23: 30$ and two nurses from 23:30 to $07: 30$. Each nurse is entitled to one $30 \mathrm{~min}$ "coffee break" and a $60 \mathrm{~min}$ meal break.

The PACU has four orderly/transporter shifts over $24 \mathrm{hr}$. Each orderly shift also lasts eight hours. The schedule has one orderly from 07:00 to 15:00 and a second orderly starts in the PACU at $11: 00$ and works until 17:00. The next orderly shift runs from 15:00 to 23:00 and the last shift runs from 23:00 to 07:00 hours. Each orderly is entitled to a $30 \mathrm{~min}$ "coffee break" and a $45 \mathrm{~min}$ meal break. The orderlies are responsible for patient and specimen transport and retrieval of radiographs, as well.

We excluded patients admitted during elective hours as a planned long stay (airway surgery, overnight monitoring, etc) because these patients would have artificially increased the length of stay for the type of anesthetic. The type of anesthetic administered was identified noted and upon the patient's arrival in the PACU. The student did not have access to the patient's chart for the sake of patient confidentiality. Departmental ethics approval was granted but hospital ethics approval was not solicited because of the quality assurance nature of the study.

The data were analyzed using the Graphpad PRISM@ statistical package. The mean and standard deviations of the various categories were calculated.

\section{Results}

There were 336 consecutive patients admitted to the PACU who were entered into the database. The average patient load increased from about three patients between 7:00 to 8:00 to 12 patients between 15:00 to 16:00. This increase in patient load was met with an increase in nursing complement from about three at 7:00 to $8: 00$ (a $1: 1$ patient:nurse ratio) to seven between 15:00 to 16:00 (a 1.7:1 patient:nurse ratio). However, the orderly complement increased from about one at 7:00 to 8:00 (a 3:1 patient:orderly ratio) 
to two at $15: 00$ to $16: 00$ (a $6: 1$ patient:orderly ratio) (Figure 1). The mean extent of delay to discharge ( \pm S.D.) increased from $0 \mathrm{~min}$ at 7:00 to $8: 00$ to $65 \pm 54$ $\min$ at 15:00 to 16:00 (Figure 2).

The mean duration $( \pm S D)$ of patient stay in the PACU following surgery was $132 \pm 61 \mathrm{~min}$ for spinal anesthetics, $154 \pm 58 \mathrm{~min}$ for epidural anesthetics, $120 \pm 73 \mathrm{~min}$ for general anesthetics, $217 \pm 202 \mathrm{~min}$ for brachial plexus nerve block, $80 \pm 54 \mathrm{~min}$ for local infiltration, and $88 \pm 51 \mathrm{~min}$ for monitored anesthesia care. However, there were too few cases of epidural anesthesia or brachial plexus nerve block to comment further on the length of stay for these methods.

Seventy-six per cent of cases studied were delayed prior to transport with $26 \%$ waiting 30 min after being considered discharge ready. The most frequent causes of delay were the orderly was busy (41\%) and an anesthesiologist had not yet assessed the patient (36\%). The other causes were the receiving floor nurses were not ready to receive a new admission $(6 \%)$, the PACU nurse was too busy to transfer a patient $(15 \%)$, and the patient was awaiting interpretation of an X-ray (2\%).

The mean \pm standard deviation total delay was $26 \pm$ $1 \mathrm{~min}$ (range 2-125 $\mathrm{min}$ ). The relative contribution in time ( $\min \pm \mathrm{SD}$ ) for each of the transporters, anesthesiologist assessment, receiving ward, PACU nurse, or radiographic interpretation were $14 \pm 1,16 \pm 1,48 \pm$ $5,17 \pm 2,28 \pm 8$ respectively.

\section{Discussion}

This is the first study to describe the experience of a Canadian institution regarding a familiar, though under- reported problem. We examined the patient flow through our PACU and found that systems problems delayed the transport of the majority of patients from the PACU. These systems problems translate into patients waiting unnecessarily in our PACU prior to transport. The causes of the prolonged stay, once identified, should be correctable.

Some might argue that it is unreasonable to expect patients to be transferred out of the PACU immediately when they are ready as this implies a cohort of anesthesiologists, nurses, and orderlies dedicated to assessing, preparing, and transporting patients from the PACU. This study was not intended to provide evidence to lobby for increased staffing and the accompanying increased costs. We simply asked how long do patients stay in our PACU and are they transferred from the PACU when they are ready? We think an average delay of $65 \mathrm{~min}$ to transport discharge ready patients between 1500 and 1600 hours is unacceptable.

We are not the first to report that patients linger in the PACU awaiting physical transport out of the

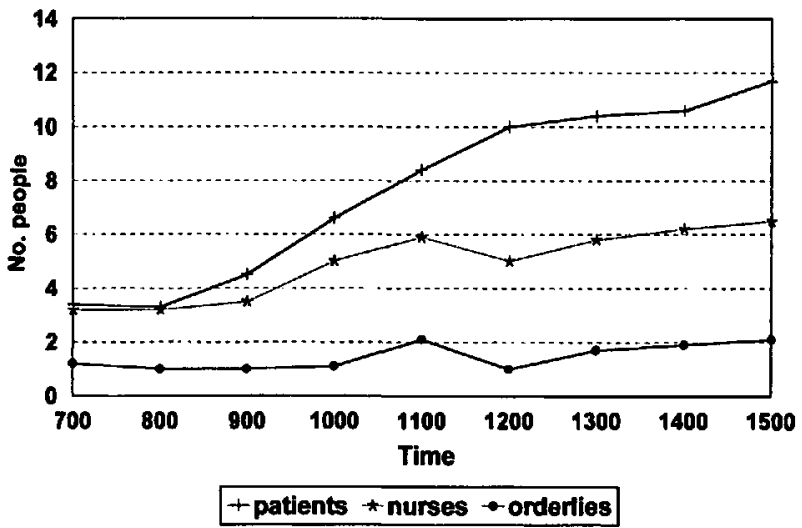

FIGURE 1 Mean numbers of patients, nurses, and orderlies in PACU during elective hours



FIGURE 2 Mean ( \pm SD) delay in PACU prior to discharge

PACU. Lubarsky et al. reported that "system problems" delayed discharge and accounted for over $25 \%$ of the time patients spend in the PACU. ${ }^{5}$ It is interesting to note that despite numerous differences between their institutions and ours, the average times spent in the PACU for general and regional anesthesia were virtually identical.

A recent article by Waddle $e t$ al. quantified and assessed factors related to PACU length of stay. ${ }^{6}$ They used a methodology similar to ours and found physician release responsible for $39 \%$ of delays. They used a 30 min window prior to considering the discharge to be delayed and they had a similar incidence of delay $(20 \%)$ in discharge in their institution.

Dexter and Tinker studied the effect of nausea and vomiting on PACU costs in an ambulatory PACU set- 
ting. ${ }^{7}$ They concluded that the distribution of patient admissions to the PACU had a far more important effect on PACU costs than anesthetic drug selection. Patient load is not only dependent upon patient admission but also upon duration of stay. If all other conditions remain constant, personnel costs per patient must decrease if patients are not waiting for transport because of systems faults.

One system fault that is most probably universal is the receiving floor nurses being unable to accept a PACU transfer. This occurs frequently in our institution at change of shift (between 15:00 to 16:00 hr). While this was the cause of the delay in only $5.4 \%$ of cases, it forced the patient to wait the longest. Discussions with ward Head Nurses are planned to eliminate this inefficiency.

Another striking feature in our study was the length of time patients with local anesthesia "parked" in our PACU mostly awaiting interpretation of a chest radiograph. These patients often are anxious about their own illnesses and are wide awake, witness to all the PACU occurrences. It is mandatory that these patients be discharged quickly. Some delay is inevitable because radiograph interpretation involves multiple processes before, and including, being read by the requesting physician. However, a special section of the PACU might be reserved for these patients if space permits, or a "fast track" process might be considered.

Some authors suggest that patients who have undergone spinal anesthesia might not need to stay in the PACU until their anesthetic has completely resolved. ${ }^{8}$ This recommendation, if proved to be safe, would have a major impact on our PACU since approximately $40 \%$ of inpatients recovering in our PACU have a spinal anesthetic.

In conclusion, system delays account for a considerable prolongation of a patient's time in the PACU. The extra time spent by the patient in the PACU is unnecessary and should be decreased where possible.

\section{Acknowledgment}

The authors gratefully acknowledge the secretarial assistance of Mrs. Sarah Scholl and the support of Ms Marisa Carnevale, Ms Susan Birt, and the other PACU nurses in the performance of the study.

\section{References}

1 Truong A, Tessler MJ, Kleiman SJ, Bensimon M. Late operating room starts: experience with an education trial. Can J Anaesth 1996; 43: 1233-6.

2 Melnik H, Tessler MJ, Wahba RM. Anesthesiologists and the time interval between cases in cardiac surgery. J Clin Anesth 1998; 10: 377-9.
3 Tessler MJ, Kardash K, Kleiman S, Rossignol M. A retrospective comparison of spinal and general anesthesia for vaginal hysterectomy: a time analysis. Anesth Analg 1995; 81: 694-6.

4 Aldrete JA, Kroulik D. A postanesthetic recovery score. Anesth Analg 1970; 49: 924-33.

5 Lubarsky DA, Glass PSA, Ginsberg B, et al. The successful implementation of pharmaceutical practice guidelines. Analysis of associated outcomes and cost savings. Anesthesiology 1997; 86: 1145-60.

6 Waddle JP, Evers AS, Piccirillo JF. Postanesthesia Care Unit length of stay: quantifying and assessing dependent factors. Anesth Analg 1998; 87: 628-33.

7 Dexter F, Tinker JH. Analysis of strategies to decrease Postanesthesia Care Unit costs. Anesthesiology 1995; 82: 94-101.

8 Alexander CM, Teller LE, Gross JB, Owen D, Cunningham $C$, Laurencio $F$. New discharge criteria decrease recovery room time after subarachnoid block. Anesthesiology 1989; 70: 640-3. 